\title{
28 Research Soure \\ Colon Squamous Cell Carcinoma Hidden Under a Small Polyp: a Case Report
}

Wen Ji ( $\square$ hellovip5@126.com )

Chongqing University

\section{Weiqing Chen}

Chongqing University

\section{Case Report}

Keywords: squamous cell carcinomas, polyp, colonoscopy, case report

Posted Date: April 13th, 2021

DOl: https://doi.org/10.21203/rs.3.rs-414300/v1

License: (c) (i) This work is licensed under a Creative Commons Attribution 4.0 International License. Read Full License 


\section{Abstract}

we report a case of colon squamous cell carcinoma incidentally diagnosed based on endoscopic polypectomy. Primary squamous cell carcinomas of the colon and rectum are extremely rare. This is not only a rare case, from this case we need to rethink how to choose the most appropriate polypectomy method.

\section{Introduction}

Primary squamous cell carcinomas of the colon and rectum are extremely rare, with an incidence of less than $1 \%$ of colorectal malignancies, and squamous cell carcinoma of the right colon is more rare than the rectum and sigmoid colon[1]. Neoplastic polyps are the main pattern of oncogenic colon cancer progression. In the screening population of the United States, the prevalence rate of neoplastic polyps may be $>50 \%$, and $70-80 \%$ of polyps are $\leq 5 \mathrm{~mm}$. Usually, such polyps have almost no cancerization. Therefore, it is controversial whether to remove such small polyps $\leq 5 \mathrm{~mm}$, and it is feared that the treatment may only bring surgical damage[2].

\section{Patient Information}

A 61-year-old man was admitted to our department after a physical examination revealed a positive fecal occult blood. Three years ago, the patient underwent colonoscopy in another hospital and found colon polyps and underwent endoscopic colonic polypectomy. Six months ago, the patient was diagnosed as systemic lupus erythematosus due to "leukocytopenia", and received long-term oral treatment with "hydroxychloroquine sulfate tablet, compound amide phosphate tablet, prednisone acetate tablet and calcitriol soft capsule". He had no significant family history.

\section{Clinical Findings And Therapeutic Intervention}

No abnormal findings were revealed throughout physical examination and laboratory tests basically normal except a slight decrease in white blood cell count $\left(3.32^{*} 10^{9} / \mathrm{L}\right)$. We arranged colonoscopy for him and found 9 polyps with a size of $0.3 \mathrm{~cm}-0.8 \mathrm{~cm}$ Polyps scattered throughout the colon, the regular structure of the glandular duct was observed under narrow band imaging mode. we removed these polyps by endoscopic mucosal resection (EMR) and endoscopic submucosal dissection (ESD). Among them, eight polyps were tubular adenomas or hyperplastic polyps, one polyp of ascending colon(Fig A)showed tubular adenoma by pathological biopsy, the deep surface of focal gland was found nest-like cells, considering the tumor lesions(Fig B), and its immunohistochemistry showed(Fig C,D): CKpan(+),P63(+) $\square$ P40(+) $\square$ Syn(-) $\square$ CgA(-) $\square$ CD56 Focal area (+) $\square$ CEA(-) $\square$ P53(+) $\square C K 20(-) \square S-100(-) \square C D 117$ Focal area (+) $\square C D 10(-) \square \mathrm{Ki}-6720-40 \%(+)$. Therefore, the final diagnosis was: the deep surface of the focal gland showed nest-like cells which consistent with squamous cell carcinoma, moderately differentiated, some parts showed basal cell like features, and other tubular adenoma components. 


\section{Follow-up And Outcomes}

Then we did a series of examinations, including gastroscopy, chest, abdomen and pelvic enhanced CT, PET-CT, and tracheoscopy. No evidence of tumor in other parts was found, which ruled out the possibility of metastatic squamous cell carcinoma of the colon. After fully communicating with the patients, we performed laparoscopic right colon cancer radical operation and intestinal adhesion lysis assisted by intraoperative colonoscopy. Postoperative pathological biopsy showed that: no clear tumor lesions were found in the deep and surrounding tissues of the original biopsy site, multinuclear giant cell reaction with fibrous hyperplasia was found in the focal area, and no tumor lesions were found at the colon, ileum and circumferential incisions. There were 18 cases of chronic inflammation of fat lymph nodes around the colon and ileum.

\section{Discussion}

In this case, the polyp of the patient was only $5 \mathrm{~mm}$. However, during EMR resection of the polyp in the patient, squamous cell carcinoma hidden under the adenoma was accidentally found, thus the diagnosis was made,Consider that if patients use APC or biopsy forceps in polypectomy, it is difficult to find squamous cell carcinoma below adenoma, which will lead to missed diagnosis and an unavoidable problem: interphase colorectal cancer, and incomplete resection of polyps (IPR) is considered to be a risk factor for inter-stage colorectal cancer[3] Incomplete resection accounted for $19 \%$ of the incidence of inter-stage colorectal cancer[4]. Therefore, it is very important to select the resection method of polyps. EMR and ESD are common and effective methods for the treatment of colorectal polyps., If EMR and ESD resection techniques are considered, it is recommended to further use magnifying endoscopy to estimate histology and infiltration depth, especially for large polyps. Block resection should be the ultimate goal, which has been proven to reduce recurrence rate and the overall resection rate of ESD is higher[5].

\section{Patient Perspective}

Originally thought it was just a small endoscopic polypectomy treatment, the final pathological results were unexpected to know that it was colon cancer, and it was a very rare squamous cell carcinoma. Fortunately, it was found in early stages, and finally cured. Thanks to the doctor for my polyp resection, colon squamous cell carcinoma hidden under a small polyp was able to find. During my hospitalization, my attending doctor worked very carefully, and the communication was very smooth, she fully communicated with me about the examination results, endoscopic diagnosis and treatment plan, including surgical operation, and obtained my informed consent. Generally speaking, I was very satisfied with the whole treatment process.

\section{Declarations}

Consent for publication: The research results will be submitted to peer-reviewed academic journals and will be published at national and international conferences. 
Availability of data and material: The data used to support the findings of this study are available from the corresponding author upon request

Competing interests: None declared.

Funding: Chongqing Science and Technology Development Foundation (cstc2017jxjl130028).

Authors' contributions: Wen $\mathrm{Ji}$ is the doctor in charge of the patient in this case and participates in the whole process of diagnosis and treatment of the disease. Weiqing Chen is the chief surgeon of the endoscopy operation of the patient, and formulates the treatment plan for the patient. Wen Ji and Weiqing Chen are responsible for writing the manuscript.

Informed consent of patients: Yes.

\section{References}

1. Int J Colorectal Dis.2015 Jan;30(1):127-30.doi:10.1007/s00384-014-2058-9.Epub 2014 Nov 13.

2. Daniel von Renteln, Heiko Pohl. Polyp Resection- Controversial Practices and Unanswered Questions. Clin TransI Gastroenterol. 2017; 8(3): 76.

3. Int J Colorectal Dis. 2019 Jul 16.

4. Gut $2014 ; 63(6) \otimes 949-56$

5. Clinical guidance on endoscopic management of colonic polyps Singapore 2020.7

\section{Figures}




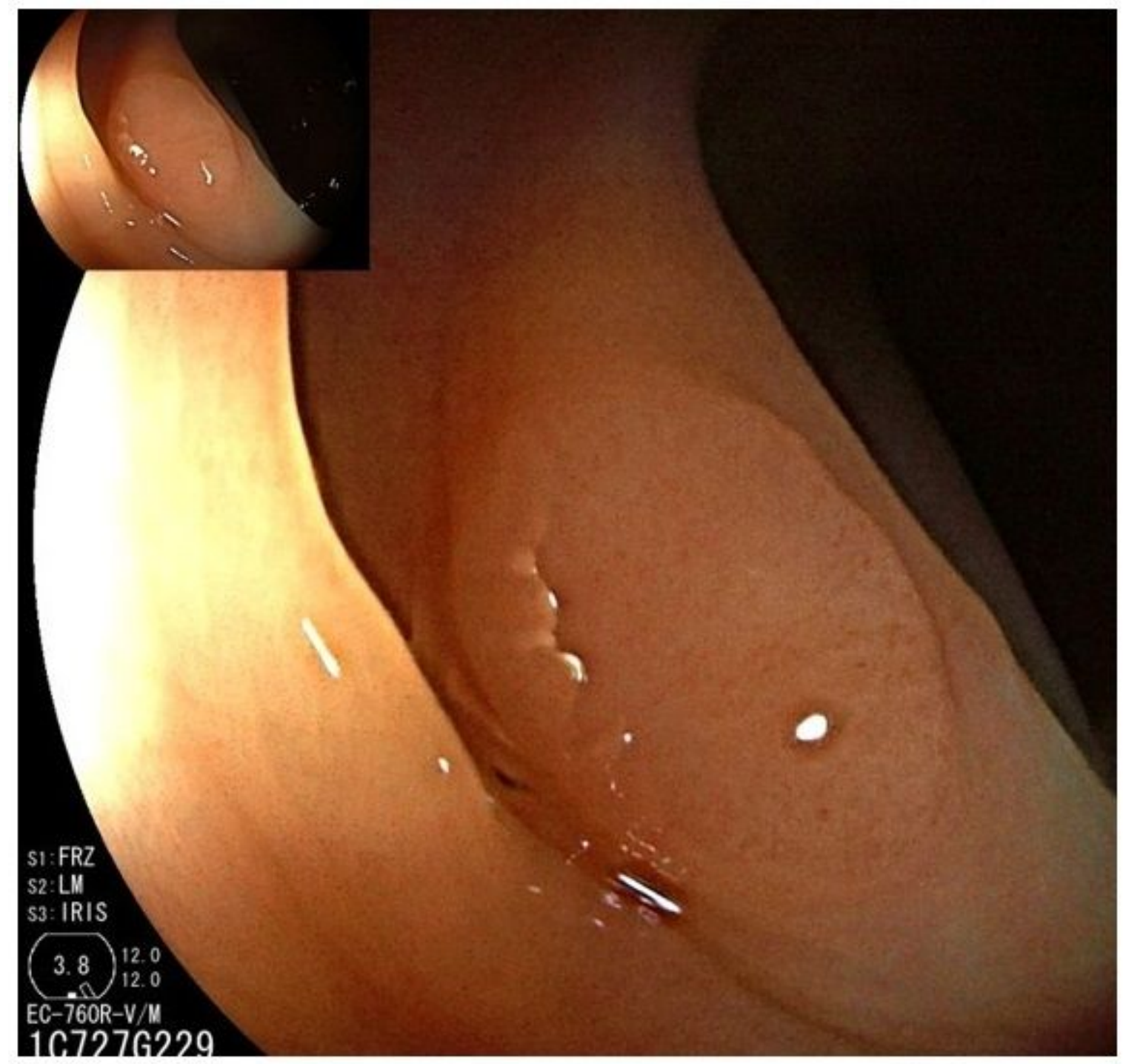

\section{Figure 1}

tubular adenoma by pathological biopsy

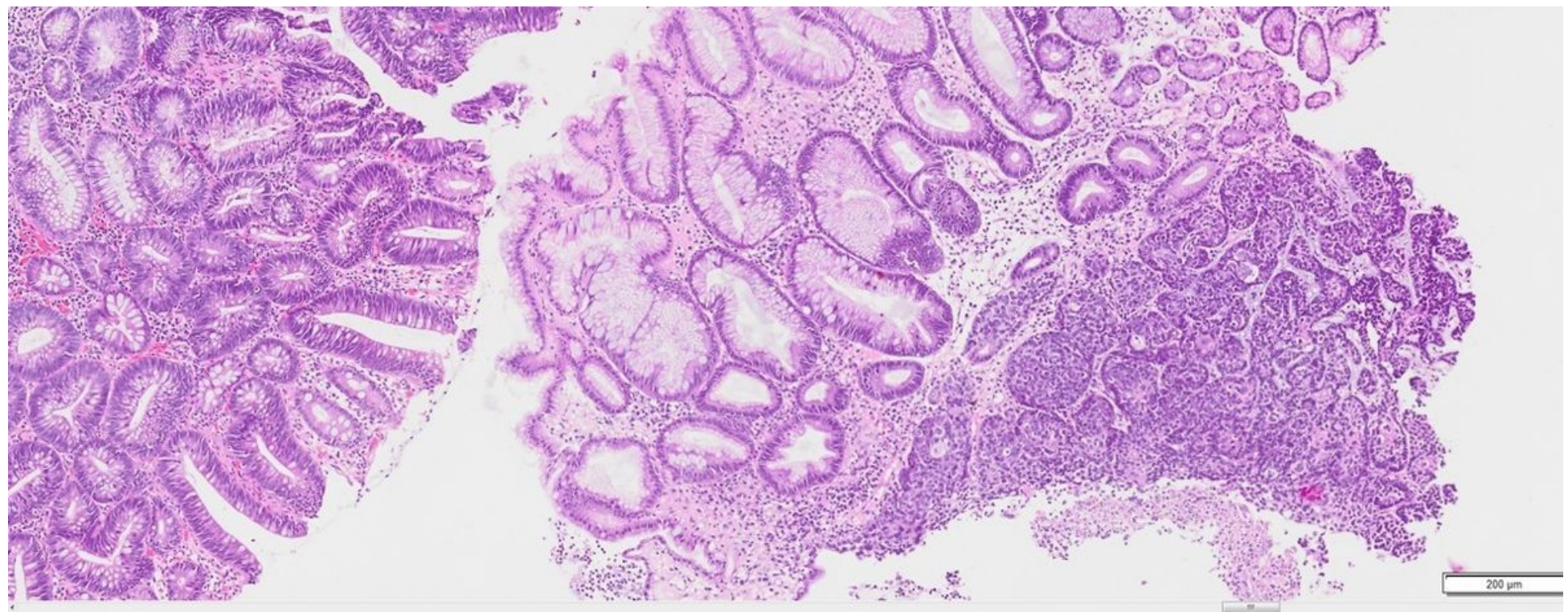


Figure 2

the deep surface of focal gland was found nest-like cells, considering the tumor lesions

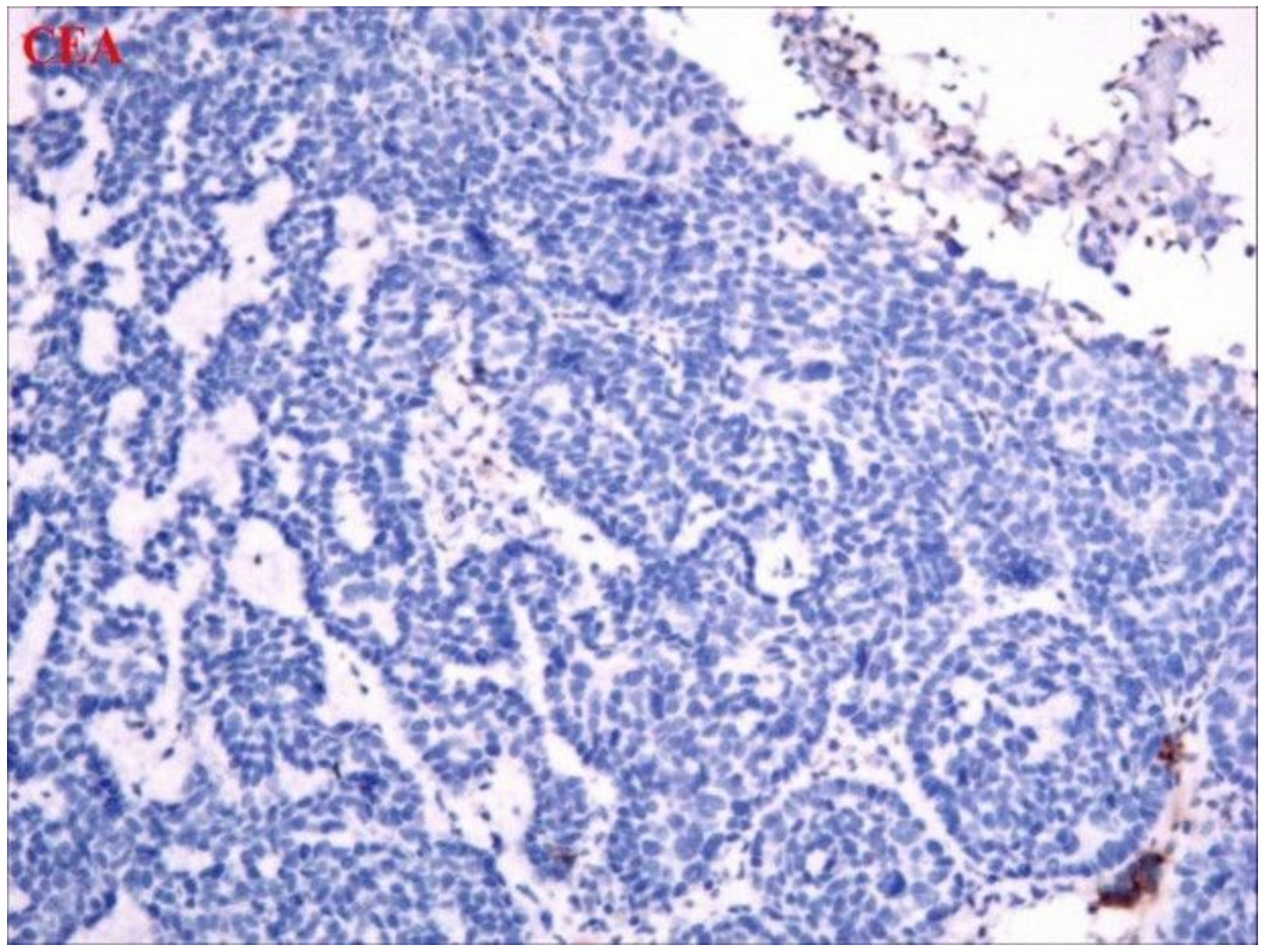

Figure 3

immunohistochemistry 


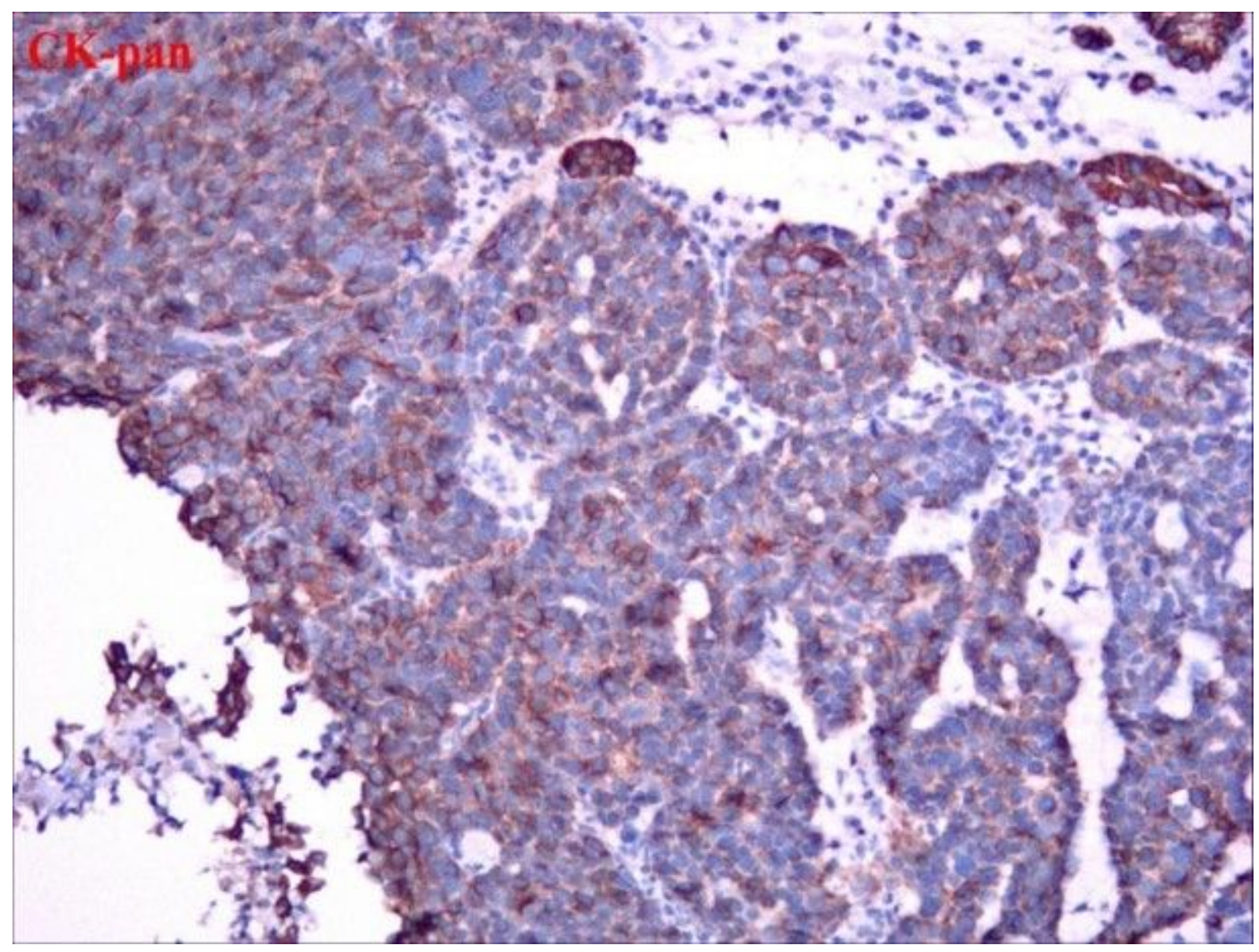

Figure 4

immunohistochemistry

\section{Supplementary Files}

This is a list of supplementary files associated with this preprint. Click to download.

- CARE.pdf 